\title{
PENGARUH POLA ASUH DAN POLA BERMAIN TERHADAP KEMAMPUAN KOMUNIKASI SOSIAL PADA ANAK AUTISM DI SURAKARTA
}

\author{
Sudarman*1, Roy Romey Daulas $\mathbf{M}^{2}$ \\ Poltekkes Kemenkes Surakarta Jurusan Terapi Wicara
}

\begin{abstract}
Background: Family is the most important role in a child's life, a place where he learns and expresses himself as a social creature, because the family provides the basis for the formation of personality, character, morals, socio-cultural and religious development as the first and foremost education place for children. The character development, morals and social development is very much influenced by parenting style and the playing pattern of child. Objective, to find out whether there is an influence of parenting style and playing patterns towards the ability of Social Communication in Children with Autism in the City of Surakarta. Methods: This type of research is a quantitative study with an observational analytic design through a cross sectional approach. This research will be conducted in the residency of Surakarta, in this study there is no intervention or treatment of respondents, and only observed once and do not follow up. Instrument, The instrument used to measure parenting style and playing patterns as well as children's social communication skills is a questionnaire. This questionnaire consists of three parts: the parenting style questionnaire aims to find out the form of parenting for children with autism. The play pattern questionnaire aims to find out the shape of the game patterns given to children with autism, and the social communication skills questionnaire aims to find out the social communication skills of children with autism. Results: Correlation statistical test using Spearmen's rho analysis on parenting style variables with children's social communication skills obtained p value (sig.) 0.006, which means the value of $p$ value $0.006<0.05$ means that there is a relationship between the form of parenting style $h$ with communication skills social children, with a positive correlation with weak strength ( $r$ count 0.393); while variable on play patterns with social communication skills obtained $p$ value $0.011<0.05$ means that there is a relationship between the form of play patterns with children's social communication skills, with a positive correlation direction and moderate strength ( $r$ count 0.363). Conclusion: Multivariate test results with multiple logistic regression showed that the $R$ Square value of 0.057, which means that the parenting style variable and playing patterns can increase social communication skills of children with autism by $0.5 \%$ and the rest are explained in other factors outside the research model.
\end{abstract}

Keywords: Parenting Style, Playing Patterns, Social Communication Skills, Autis

\section{PENDAHULUAN}

Menurut Alex Sobur dalam Sonita (2013) keluarga merupakan tempat pertama dan yang utama bagi anak untuk memperoleh pembinaan mental dan pembentukan kepribadian melalui pola asuh dan pola bermain pada anak-anak.
Pola asuh merupakan pola interaksi antara orang tua dan anak melalui sikap atau perilaku orang tua saat berinteraksi dengan anak. Sikap atau perilaku orang tua saat berinteraksi dengan anak meliputi cara penerapan aturan, pengajaran nilai/norma, pemberian perhatian dan 
kasih sayang, serta pemberian contoh sikap dan perilaku baik sehingga dijadikan panutan bagi anaknya (Tomtom 2017).

Selain pola asuh pola bermain juga mempengaruhi perkembangan komunikasi sosial anak. Jika anak diberi permain yang tidak membutuhkan interaksi dengan anak lain misalnya game, play station, $H p$, gadget dll, maka sikap dan perilaku anak akan semakin asyik di dunianya sendiri, sebaliknya jika anak sering diberikan permaianan yang melibatkan anak lain maka akan lebih cepat berkembang kepribadian dan interaksi sosialnya.

World Health Organization's dalm International Classification of Diseases (ICD-10) Autism khususnya childhood autism adanya keabnormalan dan atau gangguan perkembangan yang muncul sebelum usia tiga tahun dengan tipe karakteristik tidak normalnya tiga bidang yaitu interaksi sosial, komunikasi, dan perilaku yang diulang-ulang (World Health Organozation, 1992).

Diagnostic and Statistical Manual of Mental Disorder R-IV (DSM IV) autism merupakan salah satu dari lima jenis gangguan Pervasive Development Disorder (PDD), gangguan perkembangan perpasive (PDD) adalah istilah yang dipakai untuk menggambarkan beberapa kelompok gangguan perkembangan di bawah umbrella term PDD (APA 1994) yaitu: 1) Autistic Disorder muncul sebelum usia 3 tahun dan ditunjukkan adanya hambatan dalam interaksi sosial, komunikasi dan kemampuan bermain secara imaginatif serta adanya perilaku stereotip pada minat dan aktivitas. 2) Asperger's Syndrome yaitu hambatan perkembangan interaksi sosial dan adanya minat dan aktivitas yang terbatas, secara umum tidak menunjukkan keterlambatan bahasa dan bicara, serta memiliki tingkat intelegensia rata-rata hingga di atas ratarata. 3) Pervasive Developmental
Disorder-Not Otherwise Specified (PDDNOS) yaitu apabila tidak menunjukkan keseluruhan kriteria pada diagnosa tertentu. 4) Rett's Syndrome, lebih sering terjadi pada anak perempuan dan jarang terjadi pada anak laki-laki. Anak ini sempat mengalami perkembangan yang normal kemudian terjadi kemunduran kehilangan kemampuan yang dimilikinya, kehilangan kemampuan fungsional tangan yang digantikan dengan gerakkangerakkan tangan yang berulang-ulang pada rentang usia 1-4 tahun. 5) Childhood Disintegrative Disorder (CDD) menunjukkan perkembangan yang normal selama 2 tahun pertama usia perkembangan kemudian tiba-tiba kehilangan kemampuan yang telah dicapai sebelumnya.

Penyebab Autism Spectrum Disorders (ASD), secara pasti tidak diketahui namun autism dapat terjadi dari kombinasi berbagai faktor termasuk faktor genetik yang dipicu faktor lingkungan. Ada berbagai teori yang menjelaskan factor mempengaruhi terjadinya autism (APA 1994) yaitu: 1) Teori biologis yaitu keluarga yang terdapat anak autis memiliki resiko lebih tinggi dibandingkan populasi keluarga normal, abnormalitas genetik dapat menyebabkan abnormalitas pertumbuhan sel-sel saraf dan sel otak. 2) Teori psikososial yaitu autisme dianggap sebagai akibat hubungan yang tidak akrab antara orang tua ibu dan anak. 3) Faktor keracunan logam berat, yang dapat terjadi pada anak yang tinggal dekat daerah tambang batubara, emas dan sebagaimnya, keracunan logam berat pada makanan yang dikonsumsi ibu yang sedang hamil. 4) Faktor adanya gangguan pencernaan, pendengaran, dan penglihatan. 5) Autoimun tubuh pada anak dapat merugikan perkembangan tubuhnya sendiri karena zat-zat yang bermanfaat justru dihancurkan oleh tubuhnya sendiri. 
Pola asuh merupakan parental kontrol orang tua dalam mengontrol, membimbing dan mendampingi anakanaknya untuk melaksanakan tugas-tugas perkembangan menuju pada proses pendewasaan (Mualifah 2009). Baumrind dalam Suparyanto, (2010) jenis-jenis pola asuh, orang tua terhadap anaknya dibagi menjadi tiga jenis yaitu Pola asuh demokratis adalah pola asuh yang memprioritaskan kepentingan anak, akan tetapi tidak ragu-ragu mengendalikan mereka. Pola asuh otoriter cenderung menetapkan standar yang mutlak harus dituruti, biasanya dibarengi dengan ancaman-ancaman dan pola asuh permisif memberikan kesempatan pada anak untuk melakukan sesuatu tanpa pengawasan yang cukup.

Komunikasi sosial adalah suatu kesatuan sosial yang terdiri dua atau lebih individu yang telah mengadakan interaksi sosial yang cukup intensif dan teratur, sehingga diantara individu itu sudah terdapat pembagian tugas, struktur, dan norma-norma tertentu. (Muzafer Sherif dalam Santoso, 2006).

Ketrampilan komunikasi sosial yaitu keterampilan untuk menggunakan gaya bicara yang bervariatif, kemampuan untuk mengambil perspektif dari orang lain, kemampuan untuk memahami dan menggunakan aturan komunikasi verbal dan nonverbal dengan sesuai, kemampuan untuk menggunakan aspek structure dari Bahasa (kosa kata, sintaksis dan fonologi) untuk mencapai tujuan diatas (ASHA 2016).

Komunikasi adalah aktifitas sosial dari seseorang untuk melakukan monolog dengan dirinya sendiri, dan atau dengan melibatkan orang lain. Komunikasi dalam situasi sosial bisa lebih menantang daripada hanya memahami kata-kata orang lain. Ada aturan tidak tertulis yang mengatur interaksi dan ini dapat berubah tergantung pada keadaan dan dengan siapa berkomunikasi (Vicker, B. 2009)

Menurut Manual Diagnostik dan Statistik Gangguan Mental, Edisi ke 5 (DSM-5) (APA 2013) Gangguan komunikasi social ditandai oleh kesulitan dengan penggunaan bahasa verbal dan nonverbal untuk tujuan sosial. Kesulitan utama dalam interaksi sosial, kognisi sosial, dan pragmatik defisit spesifik terbukti dalam kemampuan individu untuk: 1) Berkomunikasi untuk tujuan sosial dengan cara yang sesuai untuk konteks sosial tertentu; 2) Mengubah komunikasi agar sesuai dengan konteks atau kebutuhan pendengar; 3) Ikuti aturan untuk percakapan dan bercerita; 4) Memahami bahasa non-verbal, dan memahami apa yang tidak secara eksplisit dinyatakan.

Berdasarkan uraian latar belakang diatas, sehingga peneliti tertarik untuk mengambil penelitian Pengaruh Pola Asuh dan Pola Bermain Terhadap Kemampuan Komunikasi Sosial pada Anak Autism di Surakarta.

\section{METODE PENELITIAN}

Jenis penelitian ini adalah penelitian kuantitatif dengan rancangan analitic observational melalui pendekatan Cross Sectional, Penelitian ini dilakukan di Kota Surakarta yang terdiri dari Sekolah kebutuhan khusus dan SLB di Surakarta pada bulan April sampai Agustus 2019.

Populasi pada penelitian ini adalah seluruh anak Autisme di Surakarta dengan menggunakan teknik purposive sampling yang artinya sampel dalam penelitian ini ditentukan dengan mempertimbangkan tujuan penelitian berdasarkan kriteriakriteria yang ditentukan terlebih dahulu, dari jumlah populasi yang memenuhi kriteria sampel sejumlah 48 orang.

Teknik pengumpulan data dalam penelitian ini melalui kuesioner yang 
sebelumnya telah dilakukan uji validitas dan reliabiltas intrumen dengan meggunakan pearson's product moment, hasil uji validitas pada kuesioner pola asuh, pola bermain serta kemampuan komunikasi social menunjukan nilai $p$ value (sig.) $\leq 0.05$, yang artinya bahwa instrument dalam penelitian ini dinyatakan valid, sedangkan hasil uji relibilitas dengan menggunakan Alpha Cronbach diperolah nilai $r$ Alpha Cronbach $\leq 0.60$, yang artinya uji relibilitas instrumen di nyatakan reliable.

\section{HASIL PENELITIAN}

Penelitian ini dilakukan di Kota Surakarta dengan lokasi di Sekolah khusus dan SLB dengan jumlah sampel sebanyak 48 responden dengan karakteristik responden berdasarkan jenis kelamin menunjukan bahwa mayoritas responden adalah perempuan yaitu sebanyak $87.5 \%$, responden laki-laki $12.5 \%$, karakteristik responden berdasarkan umur mayoritas umur responden antara 31-40 tahun sebanyak $43.8 \%$, yang berumur 41-50 tahun sebanyak $35.4 \%$, yang berumur $<30$ tahun sebanyak $14.6 \%$ dan berumur $>50$ tahun sebanyak $6.3 \%$. Karakteristik responden berdasarkan pekerjaan menunjukan bahwa mayoritas pekerjaan orang tua adalah IRT yaitu sebanyak $50.0 \%$, yang pekerjaan swasta sebanyak $50.0 \%$. Sedangkan karakteristik responden berdasarkan tingkat pendidikan menunjukan bahwa mayoritas tingkat pendidikan orang tua adalah SLTA yaitu sebanyak $47.9 \%$, berpendidikan SD sebanyak $16.7 \%$, berpendidikan Diploma sebanyak 14.6\%, berpendidikan sarjana sebanyak $14.6 \%$ dan berpendidikan SLTP sebayak 6.3\%.

Distribusi frekuensi pola asuh orang tua cukup sebanyak $70.8 \%$, pola asuh orang baik sebanyak $14.6 \%$, dan pola asuh orang tua kurang sebanyak $14.6 \%$.
Distribusi frekuensi pola bermain cukup sebanyak $64.6 \%$, pola bermain baik sebanyak $18.8 \%$, dan pola bermain kurang sebanyak $16.7 \%$. Distribusi frekuensi kemampuan komunikasi sosial pada anak autism diketahui bahwa skor maksimal 30, skor minimal 14, mean $(\mu)$ 22.06, standar deviasi $(\sigma) 3.43$, dengan distribusi frekuwensi kemampuan komunikasi sosial cukup sebanyak 52.1\%, kemampuan komunikasi sosial baik sebanyak $27.1 \%$, dan kemampuan komunikasi sosial kurang sebanyak $20.8 \%$.

Tabel 1. Hasil Uji Korelasi Rank Spearman's

\begin{tabular}{|c|c|c|c|c|}
\hline & & & $\begin{array}{l}\text { Pola } \\
\text { asuh }\end{array}$ & $\begin{array}{l}\text { Kom } \\
\text { sosial }\end{array}$ \\
\hline \multirow{6}{*}{$\begin{array}{c}\text { Spearman } \\
\text { 's rho }\end{array}$} & \multirow[t]{3}{*}{$\begin{array}{l}\text { Pola } \\
\text { asuh }\end{array}$} & $\begin{array}{l}\text { Correlation } \\
\text { Coefficient }\end{array}$ & 1.000 & $.393^{\text {** }}$ \\
\hline & & $\begin{array}{l}\text { Sig. (2- } \\
\text { tailed) }\end{array}$ & ${ }^{\circ}$ & .006 \\
\hline & & $\mathrm{N}$ & 48 & 48 \\
\hline & \multirow{3}{*}{$\begin{array}{l}\text { Komu } \\
\text { nikasi } \\
\text { sosial }\end{array}$} & $\begin{array}{l}\text { Correlation } \\
\text { Coefficient }\end{array}$ & $.393^{* *}$ & \multirow[t]{2}{*}{1.000} \\
\hline & & $\begin{array}{l}\text { Sig. (2- } \\
\text { tailed) }\end{array}$ & .006 & \\
\hline & & $\mathrm{N}$ & 48 & 48 \\
\hline
\end{tabular}

**. Correlation is significant at the 0.01 level (2tailed).

Hasil uji korelasi Rank Spearman's, menunjukan ada hubungan antara pola asuh dengan kemampuan komunikasi sosial anak autism diperoleh nilai $p$ value (sig.) $0.006<0.05$, dengan arah korelasi posistif dengan nilai $r$ hitung 0.393 , sedangkan kekuatan korelasi lemah (0.20-0.39

Tabel 2. Hasil Uji Korelasi Rank Spearman's

\begin{tabular}{|c|c|c|c|c|}
\hline & & & $\begin{array}{c}\text { Pola } \\
\text { bermain }\end{array}$ & $\begin{array}{l}\text { Kom } \\
\text { sosial }\end{array}$ \\
\hline \multirow{6}{*}{$\begin{array}{c}\text { Spearman' } \\
\text { s rho }\end{array}$} & \multirow{3}{*}{$\begin{array}{l}\text { Pola } \\
\text { bermain }\end{array}$} & $\begin{array}{l}\text { Correlation } \\
\text { Coefficient }\end{array}$ & 1.000 & $.363^{*}$ \\
\hline & & Sig. (2-tailed) & & .011 \\
\hline & & $\mathrm{N}$ & 48 & 48 \\
\hline & \multirow{3}{*}{$\begin{array}{l}\text { Komunikasi } \\
\text { sosial }\end{array}$} & $\begin{array}{l}\text { Correlation } \\
\text { Coefficient }\end{array}$ & $.363^{*}$ & 1.000 \\
\hline & & Sig. (2-tailed) & .011 & \\
\hline & & $\mathrm{N}$ & 48 & 48 \\
\hline
\end{tabular}

Hasil uji korelasi Rank Spearman's, menunjukan ada hubungan antara pola 
bermain dengan kemampuan komunikasi sosial anak autism diperoleh nilai $p$ value $0.011<0.05$, dengan arah korelasi positif dengan nilai $r$ hitung 0.363 , sedangkan kekuatan korelasinya kekuatan (0.400.599).

Tabel 3. Analisis Multivariat Dengan Regresi Logistik Ganda

\begin{tabular}{|c|c|c|c|c|}
\hline \multirow{2}{*}{$\begin{array}{c}\text { Variabel } \\
\text { independen }\end{array}$} & \multirow{2}{*}{ OR } & \multicolumn{2}{|c|}{$\begin{array}{c}\text { Tingkat } \\
\text { kepercayaan } \\
95 \%\end{array}$} & \multirow[b]{2}{*}{$\mathbf{p}$} \\
\hline & & $\begin{array}{c}\text { Batas } \\
\text { bawah }\end{array}$ & $\begin{array}{c}\text { Batas } \\
\text { atas }\end{array}$ & \\
\hline Polas asuh & 0.442 & 0.135 & 1.447 & 0.177 \\
\hline Pola bermain & 0.850 & 0.239 & 3.028 & 0.802 \\
\hline Konstanta & 2.2111 & & & \\
\hline N Observasi & 48 & & & \\
\hline $\begin{array}{l}-2 \text { Log } \\
\text { lokelihood }\end{array}$ & 63.122 & & & \\
\hline $\begin{array}{l}\text { Nagelkerke } R \\
\text { Square }\end{array}$ & 0.057 & & & \\
\hline
\end{tabular}

Analisis multivariat dengan

menggunakan Regresi logistik ganda menunjukan bahwa Nilai Nagelkerke $R$ Square sebesar 0.057 yang artinya bahwa variabel pola asuh dan pola bermain mampu meningkatkan kemampuan komunikasi sosial anak autism sebesar $0.5 \%$ dan sisanya di jelaskan pada faktor lain diluar model penelitian ini.

\section{PEMBAHASAN}

Pola asuh dari hasil penelitian ini menunjukan bahwa pola asuh orang tua tergolong cukup sebanyak 70.8\%, tergolong baik sebanyak $14.6 \%$, dan yang tergolong kurang sebanyak $14.6 \%$.

Berdasarkan hasil uji korelasi Spearmen's rho menunjukan bahwa ada hubungan yang signifikan antara pola asuh orangtua dengan kemampuan komunikasi social anak autism dengan nilai $p$-value (sig.) $0.006<0.05$, sehingga dapat disimpulkan bahawa semakin baik pola asuh yang diterapakan oleh orang tua kepada anak autism maka semakin baik pula kemampuan komunikasi sosialnya.
Hasil penelitian ini sesuai dengan hasil penelitian Setiani (2017), bahwa ada hubungan yang signifikan antara pola asuh orangtua dengan perkembangan personal sosial.

Pola bermain adalah suatu kegiatan yang dilakukan anak dengan atau tanpa menggunakan alat yang menghasilkan atau memberikan informasi, memberi kesenangan dan mengembangkan imajinasi anak secara spontan dan tanpa beban, hasil penelitian ini menunjukan bahwa pola bermain tergolong cukup sebanyak $64.6 \%$, pola bermain tergolong baik sebanyak $18.8 \%$, dan pola bermain tergolong kurang sebanyak $16.7 \%$. Hasil penelitian ini sejalan dengan hasil penelitian Kristiana (2016), tentang pola bermain pada anak autism, menunjukan bahwa anak autis menunjukkan pola bermain yang khas atau spesifik dalam bermain obyek, sosial, dan peran.

Kemampuan komunikasi sosial adalah suatu kesatuan social yang terdiri dua atau lebih individu yang telah mengadakan interaksi sosial yang cukup intensif dan teratur, sehingga diantara individu itu sudah terdapat pembagian tugas, struktur, dan norma-norma tertentu, hasil penelitian ini menunkan bahwa kemampaun komunikasi sosial mayoritas anak autism cukup yaitu sebanyak $52.1 \%$, kemampuan komunikasi sosial baik sebanyak $27.1 \%$, sedangkan yang memiliki kemampuan komunikasi sosial kurang sebanyak $20.8 \%$.

Berdasarkan hasil uji korelasi Spearmen's rho penelitian ini menunjukan bahwa ada hubungan yang signifikan antara pola bermain dengan kemampuan komunikasi sosial anak autism dengan nilai $p$-value (sig.) $0.011<0.05$, sehingga dapat disimpulkan bahawa semakin baik pola bermain yang berikan oleh orang tua kepada anak autism maka semakin baik pula kemampuan komunikasi sosialnya. 
Hasil analisis uji multivariate dengan regresi logistic berganda diketahui bahwa Nilai Nagelkerke $R$ Square sebesar 0.057 yang artinya bahwa variable pola asuh dan pola bermain mampu meningkatkan kemampuan komunikasi social anak autism sebesar $0.5 \%$. Hasil penelitian ini menunjukkan bahwa ketiga varaiabel yakni pola asuh dan pola bermain memiliki peran yang sama dalam menentukan komunikasi sosial anak autisme, walaupun hubungannya kecil.

Hubungan pola asuh akan memberikan pengaruh terhadap kemampuan komunikasi sosial anak autism, dengan memberikan pola asuh yang baik diharapkan diharapkan kemampuan komuniksi sosial anak semakin meningkat. Komunikasi sosial di perlakuan oleh setiap individu, karena selain sebagai mahluk individu seseorang juga merupakan mahluk sosial. Sebagai mahluk social manusai membutuhkan media untuk berinteraksi dengan orang lain, madia terseut adalah komunikasi sosial.

\section{American Speech Language}

Hearing Association (ASHA) (2016) komunikasi social adalah penggunaan bahasa dalam konteks sosial yang mencakup interaksi sosial, kognisi sosial, pragmatik, dan pemrosesan Bahasa. Anaka anak dengan keterampilan komunikasi sosial mencakup kemampuan untuk memvariasikan gaya bicara, mengambil perspektif orang lain, memahami dan menggunakan aturan untuk komunikasi verbal dan nonverbal secara tepat, dan menggunakan aspek struktural bahasa (misalnya, kosakata, sintaksis, dan fonologi) untuk mencapai tujuan-tujuan ini.

Anak-anak dengan gangguan komunikasi sosial akan mengalami kesulitan untuk berinteraksi dan berkomunikasi dengan orang lain, sindroma ini sering muncul pada kodisi anak Autsme. Menurut ASHA (2016) Gangguan komunikasi sosial ditandai oleh kesulitan dengan penggunaan bahasa verbal dan nonverbal untuk tujuan sosial. Kesulitan utama dalam interaksi sosial kognisi sosial dan pragmatik.

Defisit spesifik terbukti dalam kemampuan individu untuk: 1) berkomunikasi sebagai tujuan sosial dengan cara yang sesuai untuk konteks sosial tertentu; 2) mengubah komunikasi agar sesuai dengan konteks atau kebutuhan pendengar; 3) ikuti aturan untuk percakapan dan bercerita; 4) memahami bahasa non verbal atau ambigu; 5) memahami apa yang tidak secara eksplisit dinyatakan. Dalam kasus gangguan spectrum autism (ASD), masalah komunikasi sosial adalah faktor yang menentukan, bersama dengan pola perilaku berulang yang terbatas. Oleh karena itu, gangguan komunikasi sosial tidak dapat didiagnosis bersamaan dengan ASD.

\section{KESIMPULAN DAN SARAN}

Kesimpulan:

Ada hubungan yang signifikan antara pola asuh orangtua dengan kemampuan komunikasi sosial anak autism di Kota Surakarta dengan nilai $p$ value (sig.) $0.006<0.05$,

Ada hubungan antara pola bermain dengan kemampuan komunikasi sosial anak autism di Kota Surakarta dengan nilai $p$ value (sig.) $0.011<0.05$,

Nilai Nagelkerke $R$ Square sebesar 0.057 yang artinya bahwa variable pola asuh dan pola bermain mampu meningkatkan kemampuan komunikasi sosial anak autism sebesar $0.5 \%$ dan sisanya di jelaskan pada faktor lain diluar model penelitian ini.

Saran: 
Di harapkan peneliti selanjutnya untuk selalu menambah pengetahuan dan wawasan tentang permasalahan anak autism secara komprehensif, serta meningkatkan pengetahuan dalam memberikan pola asuh dan pola bermain pada anak autism agar lebih baik

Bagi orang tua, hendaknya orang tua selalu mempertimbangkan pola asuh yang diterapkan dan pola bermain yang diberikan kepada anak-anak, khusunya pada anak autism agar kemampuan komunikasi meningkat.

Bagi sekolah, diharapkan bagi pihak sekolah untuk dapat menfasilitasi dan memberikan edukasi kepada orangtua murid, agar senantiasa melibatkan orang tua atau keluarga dalam proses terapi dan memberikan edukasi tentang pola asuh yang baik dan jenis permaian yang dapat merangsang kemampuan komunikasinya anak autisme meningkat.

\section{DAFTAR RUJUKAN}

American Psychiatric Association. 2013 Diagnostic and statistical manual of mental disorders (5th ed.). Washington, DC: Author.

American Speech Language Hearing Association (ASHA).2016 Scope of practice in speech-languagepathology[Scope of Practice]. Available from www.asha.org/policy

American Psychiatric Association. 1994. Diagnostic and Statistical manual of Mental Disorder. DSM IV. Fourth. Washington : American Psychiatric Association

Direktorat pembinan pendidikan anak usia dini tahun. 2011, "Alat Permainan Edukatif untuk Kelompok Bermain" . Jakarta.

Fatimah. 2008. Dari Halaman Rumah Ke Hadapan Layar: Pola Bermain Dan Fungsinya
Kristiana 2016, Jurnal ilmiahpendidikan anak usia dini, nonformal dan informal, Volume 9 / No 1 - Juli 20.16

Muallifah 2009, Psyho Islamic Smart parenting, DIVA Press (Anggota IKAPI)

Santoso 2006, menggunakan SPSS untuk statistik Non Parametrik, Jakarta : PT Elex Media Komputindo.

Setiani 2017, Hubungan pola asuh orangtua dengan Perkembangan personal sosial Di Tk Aba Godegan Bantul.

Sonita Sera 2013, Hubungan Antara Pola Asuh Orangtua Dengan Disiplin Siswa Di Sekolah, Jurnal Ilmiah Konseling. http://ejournal.unp.ac.id/ index.php/konselor, Volume 2 Nomor Januari 2013

Suparyanto. 2010. Konsep Pola Asuh Anak. Artikel. drsuparyanto.blogspot.co.id (diakses 1 Maret 2016)

Tomtom Mochammad A. 2017 Hubungan Pola Asuh Orang Tua Dengan Perkembangan Bahasa Anak Usia Dini. Jurnal CARE (Children Advisory and Education) Volume 4 Nomor 2 Januari 2017

Vicker, B. 2009. Social communication and language characteristics associated with high functioning, verbal children and adults with autism spectrum disorder. Bloomington, IN: Indiana Resource Center for Autism.

World Health Organozation, 1992. Early Child Development. 